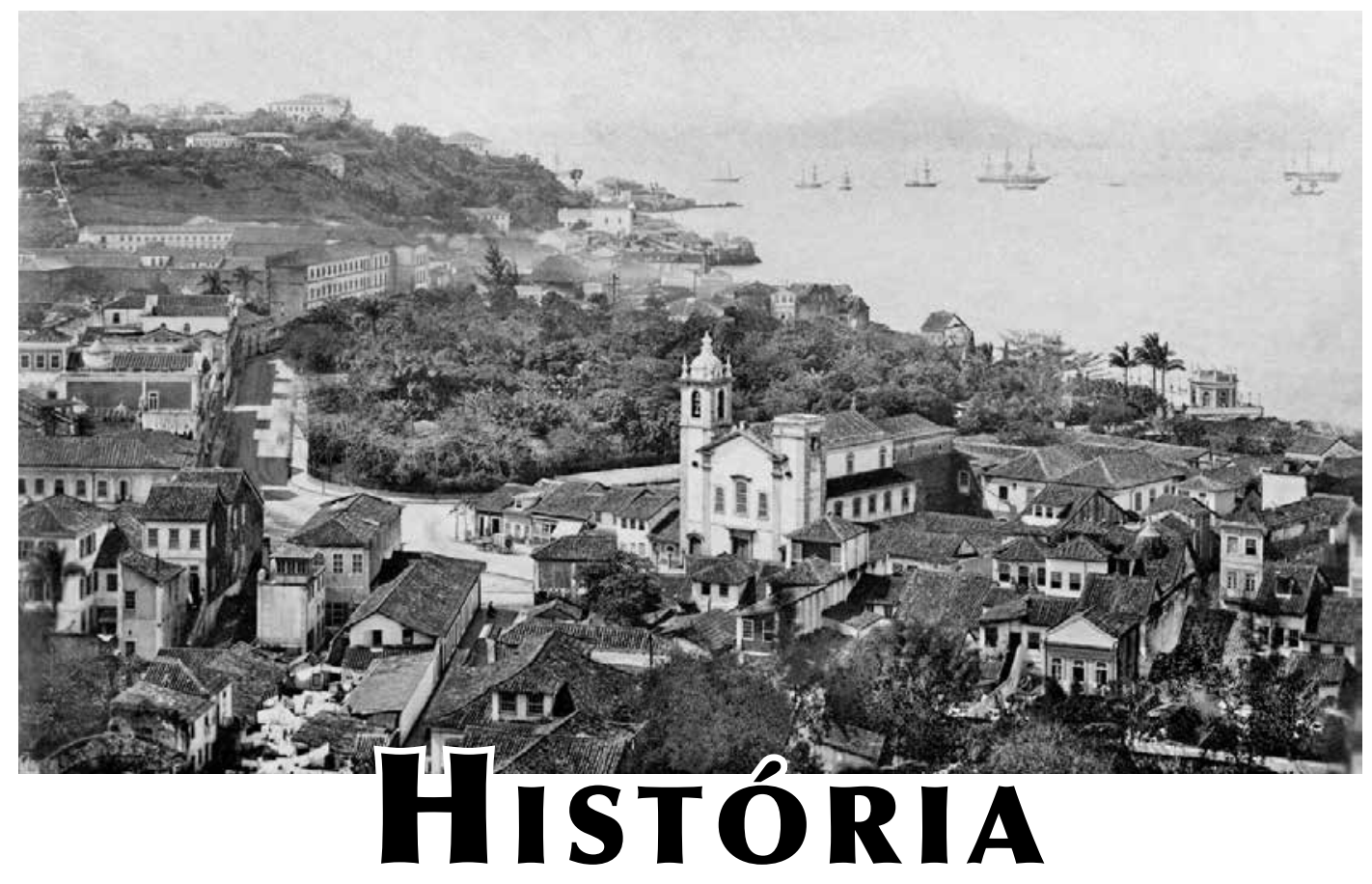




\title{
PARQUES MUNICIPAIS DE SÃO PAULO NO SÉCULO XXI
}

\author{
SÃO PAULO MUNICIPAL PARKS IN THE $21^{\text {ST }}$ CENTURY
}

\author{
Vladimir Bartalini \\ Professor Doutor FAUUSP \\ e-mail bartalini@usp.br
}

\author{
Carolina Rodrigues Borges \\ Bolsista de Iniciação Científica FAUUSP \\ e-mail carolina.rodrigues.borges@usp.br
}

\section{RESUMO}

De 1893, ano de nascimento da Inspetoria dos Jardins Públicos, até 1993, quando foi criada a Secretaria do Verde e do Meio Ambiente, os fatores intervenientes na produção dos parques públicos na cidade de São Paulo alteraram-se sensivelmente. Se durante o século XX os parques públicos, em sua maior parte, foram implantados em terrenos provenientes de loteamentos ou de desapropriação, contando basicamente com recursos orçamentários, já no final daquele século, e atualmente com maior força, passaram a ser utilizados outros expedientes para a criação e manutenção de novos parques. Para responder às novas atribuições, alteram-se a organização administrativa, as dotações orçamentárias e as fontes de recursos do órgão responsável pelas áreas verdes do município. A retrospectiva aqui realizada da atuação da municipalidade tem por objetivo fornecer subsídios para avaliar o que há de propositivo e de reativo no referente à política de implantação de novos parques públicos em São Paulo.

Palavras-chave: São Paulo, Parques urbanos, Áreas verdes, Políticas públicas, Administração municipal

\begin{abstract}
In the one hundred years between 1893, when a very modest bureau of the municipality of São Paulo started taking care of its urban green areas, and 1993, when the highest level in the municipal administration hierarchy - a Secretaria - was created to deal with green matters, factors that influence in public parks production has changed a lot. Throughout the 20th Century, public parks used to be located in plots of land that urban developers were obliged to give to the municipality, or in plots of land that the municipality bought for this special purpose. Nowadays, new administrative organization and devices are available to create urban parks. This paper verifies the most recent São Paulo municipality actions in park provision and the means used to achieve them, aiming to assess if they correspond to government initiatives or are rather reactive answers to real estate market actions.
\end{abstract}

Keywords: São Paulo, Urban parks, Green areas, Public policies, Municipal administration 


\section{PARQUES MUNICIPAIS DE SÃO PAULO NO SÉCULO XXI}

\section{Da Inspetoria de Jardins Públicos à Secretaria do Verde e do Meio Ambiente}

Exatos cem anos transcorreram desde que o município de São Paulo passou a contar com a Inspetoria de Jardins Públicos da Capital, em 1893, até a criação da Secretaria do Verde e do Meio Ambiente, em 1993.

A Inspetoria dos Jardins Públicos não passava, de início, de um simples apêndice da Secretaria da Intendência Municipal, o que, em termos de hoje, poderia ser considerado um setor vinculado ao gabinete do prefeito. $\bigcirc$ percurso deste órgão na estrutura administrativa da capital de São Paulo, nas primeiras décadas da república, dá uma ideia de como era concebido o seu papel: em 1894, todo o "pessoal dos cemitérios, matadouros e jardins" deslocou-se para a esfera da Intendência de Obras (BARROSMOIZO, 1991, p. 39); em 1896 para a Intendência de Polícia e Higiene; em 1900, já com o nome de Administração dos Jardins Públicos e Arborização, foi vinculado à recémcriada Diretoria de Obras; em 1913, a Administração dos Jardins sofreu transferência para a Diretoria de Polícia Administrativa e Higiene; em 1915, foi deslocada para a Diretoria Geral, diretamente ligada ao prefeito; em 1930 ganhou o nome de Diretoria de Jardins, Cemitérios e Mercados, subordinada à Diretoria Geral de Higiene Municipal; em 1931, passou a se chamar Diretoria dos Jardins e Cemitérios, atrelada à Diretoria de Obras e Viação; por fim, em 1935, alojada no Departamento de Obras e Serviços Municipais, foi batizada com o nome mais duradouro de Subdivisão de Parques, Jardins e Cemitérios.

Apesar das variações de nome e de endereço administrativo, o órgão responsável pelos espaços verdes da capital manteve-se relativamente estável em suas funções e na sua reduzida importância:

"Sabemos a modéstia da administração dos jardins nas primeiras décadas deste século. Uma empresa por assim dizer doméstica, na qual dois homens, o administrador e seu ajudante, formavam o quadro dirigente (técnica, contabilidade e secretaria), suficiente para um grupo de operários pequeno, mas adequado. Havia a turma de jardinagem, a dos cortadores de grama, a dos podadores, os carroceiros, a turma de limpeza, os guardas presentes em todas as praças ajardinadas e finalmente os operários que reforçavam esta ou aquela falha de pessoal, permitindo que o serviço fluísse normalmente." (ETZEL, 1982, p.195)

Dez anos mais tarde, nova reforma administrativa elevou o Departamento de Obras e Serviços ao status de secretaria municipal, que passaria a se chamar, em 1947, Secretaria de Obras. Dentro dela foi criado o Departamento de Serviços Municipais, no qual se tratavam os assuntos referentes ao verde, então promovidos de Subdivisão à Divisão de Parques, Jardins e Cemitérios. Esta nova Divisão passou a contar com duas Seções: a Seção de Cemitérios e a Seção de Parques, Jardins, Viveiros e Arborização, 
o que já denota a consolidação do reconhecimento das especificidades dos espaços livres verdes de uso comum do povo.

Ainda assim,

"apesar da maior complexidade organizacional introduzida pela reforma administrativa de Fábio Prado, o que se fazia na Divisão de Parques Jardins e Cemitérios, em 1947, não era muito diferente dos serviços que já prestava anteriormente, ou seja, administrar o viveiro de plantas, executar o plantio e fazer a manutenção da vegetação nos espaços públicos municipais - fossem praças, parques, jardins ou cemitérios -, executar pequenas obras ou consertos nas áreas ajardinadas ou arborizadas, confeccionar tutores e protetores para árvores e extinguir formigueiros" (Bartalini, 1999, p. 84).

Em 1966, criou-se a Secretaria de Serviços Municipais e, dentro dela, em 1968, o Departamento de Parques e Jardins. A mudança de nome não se limitou a uma formalidade; significou também novas competências. De fato, o novo Departamento deveria responder pelo estudo, planejamento, supervisão, orientação, construção, conservação e fiscalização de parques, jardins e canteiros, arborização de logradouros públicos, combate a animais, insetos nocivos e plantas daninhas bem como incentivar a formação de florestas e o reflorestamento. Duas Divisões compunham o Departamento de Parques e Jardins: a Divisão de Projetos e Fiscalização e a Divisão de Operação.

nome e as incumbências mantiveram-se até 1976, quando o Departamento de Parques e Jardins passou a Departamento de Parques e Áreas Verdes, conhecido até hoje como DEPAVE. A estrutura interna do Departamento tornou-se um pouco mais complexa, com o acréscimo de mais duas Divisões: a Divisão Técnica de Experimentação, Treinamento e Divulgação, e a Divisão Técnica de Manejo e Conservação de Parques.

Esta estrutura do DEPAVE manteve-se até 1993, quando foi criada a Secretaria do Verde e do Meio Ambiente - SVMA, já refletindo a importância que a questão do verde, agora englobando o ambiental em sentido amplo, passou a adquirir no meio urbano. A nova Secretaria contou de início com três Departamentos: além do DEPAVE, que viu aumentada sua importância com a coordenação de seis Divisões internas, firmando-se como o principal Departamento da nova Secretaria, foram criados os Departamentos de Controle de Qualidade Ambiental e o de Educação Ambiental.

Em termos de implantação de parques ou jardins públicos, o que ocorreu nos primeiros cem anos de existência do órgão destinado a cuidar das áreas verdes urbanas de São Paulo pode ser melhor visualizado se organizado em períodos.

\section{3 - 1935 - Da Inspetoria dos Jardins Públicos à Subdivisão dos Parques, Jardins e Cemitérios}

Em 1893, quando passaram à esfera da municipalidade, havia apenas sete jardins públicos em São Paulo: o do Paço Municipal (atual praça João Mendes), o de São 
Bento, o da Memória, o do largo do Palácio (atual Pátio do Colégio), a llha dos Amores (desaparecida), os taludes do Carmo (no início da atual avenida Rangel Pestana, também desaparecidos) e o Jardim da Luz, o maior e mais antigo. Em 1911 e 1912, os parques Siqueira Campos e Buenos Aires foram entregues ao público após a prefeitura adquiri-los de seus proprietários. Somente na década de 1920 foi inaugurado um parque com dimensões significativas, da ordem de 25 hectares, em terras públicas, nos limites da área central: o Parque Dom Pedro II. $\bigcirc$ outro parque, já bem menor, construído em terras públicas neste período foi o da Independência, a rigor um jardim formal associado ao Monumento e ao Museu do Ipiranga. No mais, até meados da década de 1920, eram chácaras ou bosques particulares que atendiam, mediante pagamento, à demanda pública por espaços verdes destinados à recreação. Fora destes espaços convencionais, fossem públicos ou privados, boa parte do lazer da população, principalmente a masculina, era praticada na beira e nas várzeas dos rios, sem aportes do poder público.

\section{5 - 1968 - Da Subdivisão dos Parques, Jardins e Cemitérios ao Departamento de Parques e Jardins}

feito mais expressivo do período foi a inauguração do Parque Ibirapuera (150 hectares), em 1954, três décadas após a execução do Parque Dom Pedro II. Praticamente mais nada aconteceu no intervalo, a não ser a compra, em 1937, da área onde, bem mais tarde, seria implantado o Parque Guarapiranga (15 hectares) e a do já existente Jardim da Aclimação (11 hectares), em 1939. No final do período, em 1966, mais um parque foi aberto: o do Bosque do Morumbi, atual Alfredo Volpi, cujo terreno proveio de loteamento aprovado em 1949. Em suma, apenas três áreas foram acrescidas ao elenco dos parques públicos em mais de trinta anos, sendo um deles desapropriado, outro implantado em terras públicas, e o terceiro em terreno doado por força de lei de loteamento. A modéstia do desempenho fica realçada quando se observa que, no período, a população de São Paulo saltara de 1.000.000 para 6.000.000 de habitantes e que a área urbanizada atingira $700.000 \mathrm{~km}^{2}$, enquanto a área dos parques municipais destinados à recreação pública mal passava de 2 km² (200 hectares).

Muito da ação da municipalidade no referente ao verde era condicionado, então, às obras associadas ao sistema viário. A abertura, o alargamento ou o prolongamento de avenidas eventualmente propiciavam um incremento na arborização viária, ou, residualmente, a criação de novas áreas verdes. Pode-se considerar que a Subdivisão de Parques, Jardins e Cemitérios quase se limitava a um órgão cujas ações vinham a reboque de decisões sobre as quais não tinha influência.

No entanto, a necessidade de reverter o atraso já se fazia sentir, tanto que, em 1966, tomou-se a iniciativa de contratar uma equipe, coordenada pelas arquitetas Miranda Martinelli Magnoli e Rosa Grena Kliass, com a atribuição específica de elaborar um plano e desenvolver projetos de áreas verdes de recreação. A equipe trabalhou na confecção do plano entre 1967 e 1969. 


\section{8 - 1993 - Do Departamento de Parques e Jardins ao Departamento de Parques e Áreas Verdes da Secretaria do Verde e do Meio Ambiente}

Trata-se do período mais profícuo na produção de novos parques durante o século $X X$. Nestes vinte e cinco anos foram abertos vinte e dois parques municipais, representando um acréscimo de 1.200 hectares destes equipamentos. $\bigcirc$ grande salto quantitativo deveu-se aos parques do Carmo (150 hectares), na zona leste, e Anhanguera (950 hectares), na zona noroeste. Os demais variavam de médio (10 a 20 hectares) a pequeno porte (menos de 3 hectares) e foram distribuídos por diferentes regiões da cidade.

Dez deles, entre os quais se incluem os dois maiores, provieram de ações judiciais envolvendo a Prefeitura. Tudo leva a supor a existência de um plano de maior fôlego. No entanto, a implantação dos novos parques não seguiu nem as recomendações do Plano de Áreas Verdes de Recreação contratado em 1966 e elaborado entre 1967 e 1969, nem as do Plano Urbanístico Básico de 1968, nem as do Plano Diretor de Desenvolvimento Integrado de 1972, nem as do Plano Diretor de 1985. Se houve planos, pode-se dizer que não ultrapassaram as contingências dos mandatos de cada prefeito.

Se se considerarem as desapropriações e outras ações judiciais para obter áreas para novos parques como sinais de forte intencionalidade do poder público neste setor, o maior empenho ocorreu em meados da década de 1970. De fato, daí provieram quase $50 \%$ dos parques implantados no período. A concentração nesta década pode ser em parte explicada pelas condições favoráveis aos cofres municipais advindas da reforma tributária de 1967, que repassava às prefeituras parte das arrecadações federais e estaduais, seguida da chamada fase expansiva do modelo industrial brasileiro, entre 1968 e 1973. Havia, portanto, recursos para desapropriações, como também um ambiente facilitador para a transferência dos frutos de ações judiciais promovidas em diferentes esferas do poder - como a que originou o Parque Anhanguera, envolvendo os governos federal, estadual e municipal - num momento específico da vida política brasileira, em que a escolha tanto dos governadores dos estados como dos prefeitos das capitais passavam obrigatoriamente pelo aval do governo federal.

Os demais parques inaugurados no período, representando mais de 50\% do total, originaram-se de espaços livres de loteamentos, pelo cumprimento da legislação municipal que impunha a doação de percentuais de áreas verdes nas operações de parcelamento do solo. Eram, em geral, áreas de pequenas dimensões, em torno de 3 hectares, só excepcionalmente atingindo 10 ou, no máximo, 13 hectares.

Dentre estes doze casos, dez referem-se a loteamentos abertos entre 1950 e 1960. Antes de se tornarem parques, sua condição variava entre áreas públicas abandonadas, mas poupadas pelas invasões, ou áreas utilizadas como depósitos de bota-foras, às vezes pela própria Prefeitura, ou então já eram "praças", isto, espaços minimamente equipados, que, por solicitação de associações de bairro, foram cercadas e contempladas com uma administração própria, galgando a condição de parques. 
Já que o maior entre os parques, o Anhanguera, proveio de execução de dívida, ou seja, de confisco de propriedade, a sua localização não passou por uma deliberação do DEPAVE. Tampouco ele teve ingerência sobre a localização da quase totalidade das áreas livres de loteamento que se tornaram parques, uma vez que a abertura dos loteamentos era comandada pelos interesses de quem loteava. Além disto, a própria delimitação da área a ser doada como "verde" ficava a critério do loteador. Somente em 1981 aprovou-se uma lei - a Lei municipal n. 9413 - estipulando que 50\% das áreas verdes de doação compulsória deveriam ser escolhidas pelos órgãos competentes do executivo municipal.

\section{OS PARQUES DA SECRETARIA DO VERDE E DO MEIO AMBIENTE - SVMA}

As mudanças provocadas pela criação da Secretaria do Verde e do Meio Ambiente - SVMA em 1993, como era de se esperar, não se fizeram sentir de imediato. Os dois primeiros parques inaugurados após o advento da nova Secretaria, um em 1995 e o outro em 2002, também resultaram de operações de parcelamento ocorridas no período anterior, eram "tradicionais" (termo empregado pela própria Secretaria do Verde e do Meio Ambiente para fazer a diferenciação com os parques lineares, associados a cursos d'água, e com os parques "naturais", caracterizados pelas grandes dimensões e pela presença significativa de vegetação nativa) e de pequenas dimensões.

Um terceiro, o Tiquatira, de 2004-2005, já escapa da classificação "tradicional". É um "parque linear", ao longo do ribeirão Tiquatira, com uma área total de mais de 30 hectares. Foi construído com verbas do Programa de Canalização de Córregos - PROCAV. Este programa teve início em 1987 com investimentos que vinham majoritariamente do Banco Interamericano de Desenvolvimento - BID, seguidos pelos da Caixa Econômica Federal e da Prefeitura de São Paulo. Embora se trate de um parque, não se pode dizer que tenha se originado em decorrência de uma política formulada pela SVMA, mesmo porque o PROCAV, que o gerou, foi coordenado pela Secretaria de Infraestrutura Urbana, e os objetivos do programa - canalização de córregos e abertura de avenidas - não são propriamente, ou estritamente, objetivos ambientais.

O Balanço das Ações do Meio Ambiente, de janeiro de 2005 a maio de 2009, apresentado pela SVMA, aponta o salto, naqueles quatro anos, de 34 para 58 parques municipais em São Paulo, ou seja, teriam sido inaugurados mais 24. Dados recentes fornecidos pelo DEPAVE informam que, entre 2005 e 2010, foram abertos 52 parques novos, passando-se de 1.500 hectares de parques implantados até 2004 para 2.400 hectares até 2010. Portanto, entre 2009 e 2010 teriam sido concluídos 28 parques que estavam em fase de implantação quando da publicação do balanço. Sem entrar no mérito da qualidade dos projetos e da execução, trata-se sem dúvida de um considerável aumento quantitativo.

É preciso verificar, ainda que de um modo preliminar, em que consistem e por quais mecanismos nasceram estes novos parques. Antes, porém, será traçado um breve pa- 
norama das mudanças nas atribuições, na estrutura e nas fontes de recursos da SVMA ocorridas durante esta primeira década do século.

\section{Consolidação da estrutura}

A SVMA contou, no seu início, com três Departamentos:

Parques e Áreas Verdes - DEPAVE

Controle de Qualidade Ambiental - DECONT

Educação Ambiental - DEAPLA.

O DEPAVE passou a ter então sob seu comando seis Divisões. Nota-se na nova estrutura a introdução de assuntos que anteriormente não eram contemplados, ligados ao manejo biofísico, refletindo as preocupações de ordem ambiental que, despontando mundialmente na década de 1970, ganharam notoriedade no Brasil a partir da realização da Eco 92, no Rio de Janeiro.

Ao longo dos dezessete anos de existência, a SVMA e os seus órgãos colegiados foram remanejados. Apresentar sua nova organização possibilita, por comparação, perceber as mudanças ocorridas.

Após sua reestruturação em 2009, a SVMA passou a ser composta por sete Departamentos:

Departamento de Controle da Qualidade Ambiental - DECONT;

Departamento de Educação Ambiental e Cultura de Paz - Universidade Aberta do Meio Ambiente e Cultura de Paz - UMAPAZ;

Departamento de Parques e Áreas Verdes - DEPAVE;

Departamento de Planejamento Ambiental - DEPLAN;

Departamento de Gestão Descentralizada - DGD;

Departamento de Administração e Finanças - DAF;

Departamento de Participação e Fomento a Políticas Públicas.

Estão ainda vinculados à SVMA os seguintes órgãos que têm peso tanto na execução da política quanto na administração dos recursos da Secretaria:

Conselho Municipal do Meio Ambiente e Desenvolvimento Sustentável - CADES, criado pela Lei n. 11.426, de 1993, e legislação subsequente;

Conselho do Fundo Especial do Meio Ambiente e Desenvolvimento Sustentável CONFEMA, criado pela Lei n. 13.155, de 29 de junho de 2001, e legislação subsequente.

Para efeito do assunto aqui tratado, convém centrar a atenção no Departamento de Parques e Áreas Verdes - DEPAVE e no Departamento de Planejamento Ambiental - DEPLAN.

O DEPAVE viu ampliado o número de suas Divisões para oito. $\bigcirc$ Departamento manteve as atribuições básicas de produzir ou contratar projetos, gerenciar obras, produzir mudas de plantas, promover pesquisas e ações com vistas à proteção e ao equilíbrio da paisagem e do ambiente. Mas duas dentre as funções que the foram designadas chamam a atenção.

A primeira, a cargo da Divisão Técnica de Proteção e Avaliação Ambiental, diz respeito à avaliação de empreendimentos e ao cálculo de compensações ambientais nos 
casos que envolvem corte de vegetação. Daí se originam os Termos de Compensação Ambiental, uma das novas fontes de recursos aplicados em áreas verdes.

A outra função de destaque é a de executar a política referente ao Sistema de Áreas Verdes, de onde se infere a necessária existência de uma políitica. Se, por um lado, isto não é uma novidade no nível discursivo ou meramente formal das leis e decretos, por outro, a criação de um novo Departamento, o de Planejamento Ambiental - DEPLAN, não deixa de ser um avanço no sentido da concretização desta intenção. Mais significativo ainda, por óbvio que pareça, é o fato da políitica do verde passar, finalmente, a ser formulada por um órgão afeito ao assunto e não vir no rastro de políticas alheias. Resta avaliar o que este rearranjo produziu de efetivo.

Como as atribuições do DEPLAN prevêem a sua interação com outros órgãos da Prefeitura para a formulação das políticas setoriais, ocorrem forçosamente intersecções com os programas de outras Secretarias, notadamente as de Habitação e de Infraestrutura, com suas afinidades e conflitos. Daí, também, resultam vínculos com a Secretaria do Planejamento para a aplicação dos instrumentos urbanísticos e ambientais previstos no Plano Diretor Estratégico.

Entre as determinações do Plano Diretor Estratégico de 2002 e dos Planos Regionais Estratégicos de 2004, conta-se a implantação dos "parques lineares" ao longo dos cursos d'água. Viabilizá-los no âmbito da Secretaria do Verde e do Meio Ambiente é atribuição do DEPLAN, o que exige articulação com programas da Secretaria da Habitação, uma vez que grande parte dos vales fluviais sofreu ocupação por favelas, e com programas da Secretaria de Infraestrutura, pois com os vales também coincidem muitos projetos desta pasta, sobretudo os viários.

\section{As novas fontes de recursos e os novos parques}

Com o aumento das suas atribuições, a SVMA viu crescer a parte do orçamento municipal que the é destinada anualmente. Vinte e dois dos novos parques abertos a partir de 2005, ou seja, mais de $40 \%$ deles, contaram, integral ou parcialmente, com verbas de dotação orçamentária para a sua implantação.

Afora o aumento dos aportes normais advindos do orçamento municipal, a Secretaria pode contar com outras fontes de recursos para a execução da sua política no referente às áreas verdes.

Os Termos de Compensação Ambiental - TCAs, já citados, são uma delas. Embora prioritariamente a compensação se dê na forma de plantio de exemplares arbóreos, há casos em que os TCAs são aplicados em obras e serviços de requalificação ou de implantação de áreas verdes, ou ainda na aquisição de terrenos para parques. Treze dentre os 51 parques municipais abertos nos últimos cinco anos, portanto, mais de 20\%, contaram com a participação de verbas de TCAs para a sua implantação.

Igualmente significativos são os recursos provenientes do Fundo de Desenvolvimento Urbano - FUNDURB. As reservas deste Fundo se originam da compra de potencial construtivo por parte de empreendedores que desejam construir utilizando coeficiente de aproveitamento superior ao legalmente estabelecido. A quantia acordada pela 
compra é depositada em dinheiro no FUNDURB que, desde 2006, faz o repasse de parte do Fundo para a implantação dos "parques lineares". Catorze novos "parques lineares", ou seja, mais de $25 \%$ do total de parques, foram executados, em parte ou na totalidade, com dinheiro do FUNDURB.

Há ainda parcerias, acordos e convênios firmados entre a Prefeitura e empresas públicas e privadas ou concessionárias de serviços públicos, ou ainda doações, que acabam por gerar novos parques. Seis foram os parques derivados destes expedientes nos últimos cinco anos.

Por fim, a SVMA conta também com os recursos da venda de créditos de carbono em leilão. No caso de São Paulo, os créditos provêm da exploração de gás produzido nos aterros sanitários Bandeirantes e São João, e são repartidos entre o Município e as empresas que administram os aterros. Com a parte arrecadada pelo Município é financiada a recuperação ambiental das redondezas dos aterros, o que pode incluir a produção de novas áreas verdes.

Em janeiro de 2008 foi lançado o Programa 100 Parques, após proceder-se à identificação de diversas áreas com necessidade de preservação e/ou com potencial para a implantação de parques. A execução do Programa está concentrada, como já foi dito, em dois Departamentos: o Departamento de Planejamento Ambiental (DEPLAN) e o Departamento de Parques e Áreas Verdes (DEPAVE), que assumem diferentes funções no processo. O DEPLAN é responsável pelo planejamento geral do Programa com a identificação das áreas, o levantamento de informações para diagnóstico, os encaminhamentos necessários para desapropriações e as interfaces com os demais atores do poder público e da iniciativa privada. O DEPAVE se incumbe do diagnóstico das áreas, do desenvolvimento dos projetos, da fiscalização das obras, e da gestão de uso dos parques.

Quanto aos terrenos onde foram implantados os parques criados entre 2005 e 2010, mais de 60\% dos casos são espaços livres públicos de loteamentos. Aqueles que, em sua totalidade ou em parte, foram desapropriados representam algo em torno de 18\%. Os demais derivaram de concessões de uso envolvendo algum tipo de negociação entre Prefeitura e Estado, entre Prefeitura e concessionárias de serviços, ou entre Prefeitura e companhias de capital público e privado.

Para completar as informações sobre a produção dos parques municipais de São Paulo nesta primeira década do século, apresenta-se uma caracterização sumária das suas tipologias, dimensões e distribuição espacial.

A novidade, do ponto de vista da tipologia, são os "parques lineares", em decorrência do estabelecido no Plano Diretor Estratégico do Município, de 2002, e nos Planos Regionais das Sub-prefeituras, de 2004. Dentre os novos parques implantados, 21, ou seja, cerca de 40\%, enquadram-se nesta classificação. Dos 21 "parques lineares", 11 situam-se na zona leste, 6 na zona sul, 3 na zona norte e 1 na centro-oeste. Na quase totalidade derivam de espaços livres de loteamento, sendo que em alguns casos houve complementação da área por meio de desapropriação. Suas dimensões são variáveis, mas a maior parte possui área inferior a 10 hectares, embora alguns dos "parques line- 
ares" - notadamente o Tiquatira e o Zilda Arns, na zona leste, e o Pinheirinho d'Água, na zona norte - estejam entre os maiores parques inaugurados nesta década.

Com exceção dos 400 hectares de mata contíguos ao parque do Carmo, na zona leste, aos quais se atribui a classificação de "parque natural", todos os demais são considerados "parques tradicionais". Em sua maior parte são espaços livres de loteamento, com dimensões inferiores a 10 hectares. As exceções, em termos de dimensões, são poucas: destacam-se o Vila do Rodeio, na Cidade Tiradentes, zona leste, com mais de 60 hectares e o do Trabalhador, também na zona leste, com mais de 20 hectares.

Os novos "parques tradicionais" estão distribuídos de maneira desigual pelas regiões do município de São Paulo. Dos 29 parques desta tipologia, 10 encontram-se na zona leste, historicamente a mais carente em número de parques. A segunda região que concentra maior número de novos "parques tradicionais" é a zona centro-oeste, com 8 deles, seguida pela zona norte, com 5 e da zona sul, com 5 também.

Além dos 52 novos parques implantados entre 2005 e 2010, há atualmente 18 parques em obras, dos quais 50\% são "lineares" e 50\% "tradicionais", distribuídos, em sua maior parte, nas zonas sul e leste. Devem contribuir, no total, com mais 540 hectares de parques.

Há ainda 27 parques em estudo, sendo 15 "lineares", 7 "tradicionais" e 5 "naturais". Devem acrescentar mais de 3.000 hectares ao total de parques de São Paulo. A grande contribuição, em área, provirá dos parques "naturais", concentrados, na quase totalidade, na zona sul, frutos de compensação ambiental pela passagem do Rodoanel.

\section{UM BALANÇO PROVISÓRIO}

É inegável o aumento significativo do número e da área total de parques desde a criação da SVMA. É igualmente notável a concentração deste crescimento nos últimos 6 anos. Vários fatores devem ter contribuído para este resultado, mas um dos mais decisivos parece ter sido a projeção que a questão ambiental vem adquirindo, o que se reflete na própria consolidação da Secretaria e na sua maior expressão política. Em consequência, a SVMA passou a ser melhor aquinhoada na dotação orçamentária e pôde contar com maior diversidade de fontes de recursos.

A comparação quantitativa com a produção dos períodos anteriores, mesmo se se considerar o mais produtivo deles, de 1968 a 1993, evidencia uma grande desproporção. Por outro lado, é curioso o resultado se o cotejamento se dá levando em conta a procedência das terras onde foram implantados os parques e como se efetivou a sua implantação.

Viu-se que mais de 60\% dos parques implantados, entre 2005 e 2010, são espaços livres públicos de loteamentos, ou seja, trata-se de terrenos doados à Prefeitura por ocasião da abertura de loteamentos. É o loteador, ou, se se quiser, o mercado, quem define a ocasião e o local do loteamento do qual resultará o espaço livre de um futuro parque. Há de se reconhecer à Prefeitura o mérito de realizar um parque numa área a isto destinada por lei, mas a ela não coube a iniciativa e sim apenas uma função 
reguladora do processo que gerou aquela terra a ser transformada em parque. A porcentagem de casos de parques implantados em espaços livres de loteamento a partir da criação da SVMA é praticamente a mesma da verificada no período de 1968 a 1993.

Diferente é o caso das desapropriações, pois aqui, em princípio, o querer é da municipalidade. Ocorre que os casos de novos parques implantados em terrenos derivados destas ações, representam, como foi visto, 18\% do total, enquanto no período 1968-1993 chegavam a quase 40\%.

Considere-se agora o papel dos Termos de Compensação Ambiental - TCAs, nova fonte geradora de recursos para a produção de parques. Em que pese serem um avanço no sentido de compensar ações agressivas ao meio ambiente, não deixam de ser compensações, isto é, não reparam o dano, que é sempre irreversível; na melhor das hipóteses, levam a um empate e não a avanços efetivos. Em princípio, a ação compensatória é realizada na própria bacia em que ocorreu o dano. Novamente, a escolha do local ou da região que sofrerá perda ambiental e, por consequência, receberá compensação, fica nas mãos do empreendedor, restando à Prefeitura contentar-se em cobrar a indenização devida. O caso dos "parques naturais" na região sul, que representam mais de $70 \%$ da área total dos parques em fase de estudo ou projeto, é ilustrativo. Provêm de TCAs assinados pela implantação do tramo sul do Rodoanel, iniciativa do Estado totalmente desvinculada dos interesses ambientais.

As ações da municipalidade, no que concerne ao verde, também encontram limites importantes no FUNDURB, de cujas verbas depende a implantação dos "parques lineares", pois a arrecadação deste Fundo fica na dependência da temperatura do mercado imobiliário: o seu desaquecimento poderá comprometer o cumprimento de metas estabelecidas pela SVMA.

Dir-se-á que estas são as regras do jogo, que o poder público municipal não joga sozinho e que até chega a estabelecer algumas normas. De todo modo, não parece sensato concluir daí que ele tem tomado a iniciativa das jogadas, no que diz respeito aos parques públicos. Sua posição é antes, ou continua a ser, caracteristicamente defensiva.

Não se deve minimizar os feitos concretos da SVMA, via DEPAVE, na produção de parques em São Paulo, tampouco o planejamento das ações, que ao menos agora conta com um endereço no DEPLAN. Por ali se realizam a identificação das áreas que interessam ambientalmente, o levantamento de informações para diagnóstico, os encaminhamentos necessários para desapropriações e as interfaces com os demais atores intervenientes. Estar preparado para reagir é melhor do que não estar, embora melhor ainda fosse tomar a dianteira. É, em parte, o que vem acontecendo na franja do Parque Estadual da Serra da Cantareira, ao norte do município. Propõe-se ali um colar de parques que funcionaria como amortecedor de impactos sobre aquela reserva florestal. Dois "parques lineares", em execução, integrarão esta faixa protetora, que se completaria com outros cinco parques a serem criados em terrenos sobre os quais já incidem Decretos de Utilidade Pública - DUPs. Mas, como em qualquer jogo, o resultado não está garantido: $\bigcirc$ Departamento de Estrada de Rodagens do Estado de São Paulo - DERSA, responsável pela implantação do Rodoanel, tem planos de fazer 
passar o seu tramo norte pelo sopé da Cantareira, para o que contaria com o trabalho facilitador dos DUPs originalmente motivados por finalidades ambientais. $\bigcirc$ desfecho deste caso poderá indicar a permanência, sob outras formas, do velho modelo de lidar com o verde em nossas cidades ou, ao contrário, sinais consistentes de mudança.

\section{Bibliografia}

BARROS, Edgard Luiz de. Desenvolvimento e planejamento urbano durante a república velha. Revista do Arquivo Municipal, São Paulo: Divisão do Arquivo Histórico, n. 195, p. 35-48, 1982.

BARROS, Liliane S. L. de; MOIZO, Rosana P. A.. Formação administrativa da cidade de São Paulo 1554-1954. Revista do Arquivo Municipal, São Paulo: Departamento do Patrimônio Histórico Municipal, n. 199, p. 11 - $112,1991$.

BARTALINI, Vladimir. Parques Públicos Municipais de São Paulo. A ação da municipalidade no provimento de áreas verdes de recreação. 1999. 221 p. Tese (Doutorado) - Faculdade de Arquitetura e Urbanismo da Universidade de São Paulo. São Paulo. 1999.

COELHO, Leonardo Loyolla. Compensação Ambiental. Uma alternativa para viabilização de espaços livres públicos para convívio e lazer na cidade de São Paulo. 2008. 209 p.

dade de Arquitetura e Urbanismo da Universidade de São Paulo. São Paulo. 2008.

Dissertação (Mestrado) - Facul-

ETZEL, Eduardo. O verde na cidade de São Paulo. Revista do Arquivo Municipal, São Paulo: Divisão do Arquivo Histórico, n. 195, p. 51-76, 1982.

SÃO PAULO, PREFEITURA DO MUNICÍPIO - Secretaria Municipal de Planejamento Urbano. Plano Diretor Estratégico do Município de São Paulo 2002-2012. São Paulo, SEMPLA. Paulo, SVMA, 2010

Secretaria do Verde e do Meio Ambiente. Guia dos Parques Municipais de São Paulo, v. 2. São Secretaria do Verde e do Meio Ambiente. 1.600 dias: balanço das ações do meio ambiente, janeiro de 2005 a maio de 2009.

. Secretaria do Verde e do Meio Ambiente. Programa 100 Parques. Plano de parques para o município de São Paulo. Documento interno. 2010. 